\title{
Strain rate dependent shear banding behavior of a Zr-based bulk metallic glass composite
}

\author{
J.H. Chen, M.Q. Jiang, Y. Chen, L.H. Dai* \\ State Key Laboratory of Nonlinear Mechanics, Institute of Mechanics, Chinese Academy of Sciences, Beijing 100190, China
}

\section{A R T I C L E I N F O}

\section{Article history:}

Received 4 January 2013

Received in revised form

22 March 2013

Accepted 28 March 2013

Available online 9 April 2013

Keywords:

Metallic glass composite

Mechanical behavior

Strain rate effect

Shear bands

Plasticity

\begin{abstract}
A B S T R A C T
In this study, the uniaxial compressive experiments were conducted on a $\mathrm{Zr}_{39.6} \mathrm{Ti}_{33.9} \mathrm{Nb}_{7.6} \mathrm{Cu}_{6.4} \mathrm{Be}_{12.5}$ bulk metallic glass matrix composite with in situ formed ductile dendritic crystalline phase at quasistatic and dynamic strain rates. The results demonstrate that the plasticity of this composite is sensitive to the applied strain rate, which is found to result from the strain rate dependent shear banding behavior. By analyzing the energy dissipation during shear band propagation, i.e., shear band toughness, in the composite, the possible mechanism of the rate dependent shear banding behavior was unveiled. Our present results may increase the understanding of the deformation and fracture mechanism of bulk metallic glass composites.
\end{abstract}

(c) 2013 Elsevier B.V. All rights reserved.

\section{Introduction}

Bulk metallic glasses (BMGs) have attracted large interests due to their unique mechanical and physical properties [1-6], showing widespread potential applications [7-11]. However, this is impeded by the poor room-temperature plasticity, which results from the easy nucleation and fast propagation of shear band in this type of amorphous materials [12-18]. One of the effective ways to surmount this problem is to develop BMG composites by introducing in situ or ex situ second-phases (and/or particles) [7,19-28]. The existence of second-phases can increase the nucleation rate of shear bands due to enhanced interfaces, and on the other hand, retard their propagation to a great extent. Both aspects facilitate the formation of multiple shear bands that can accommodate more plastic strain and contribute to macroscopic plasticity. This plasticity-enhancement method however poses a challenge with increasing the loading strain rates [29-31]. For example, according to the study by Qiao et al. [31], the multiplication of shear bands can be observed for the in-situ Zr-based BMG composite under quasistatic compression, resulting in a plastic strain as high as $30 \%$. However, single-shear-dominated catastrophic facture happens for this composite in the dynamic case. Therefore, it is necessary to reveal the mechanism for this rate dependent shear banding behavior. In fact, the BMG composite is a complex system which contains a glassy matrix and a second-phase (usually crystalline). The response of the two structures to shear-banding instability is different fundamentally [13-15,32-39]. The shear band in crystalline

\footnotetext{
* Corresponding author. Tel.: +86 10 82543958; fax: +86 1082543977.

E-mail address: lhdai@lnm.imech.ac.cn (L.H. Dai)
}

phase essentially is thermal-plastic instability, whereas that in BMG has structural-softening origin. Such a difference maybe results in rate dependent shear banding behavior, which deserves further investigations. In the present work, we indeed observed the different shear banding behaviors in a $\mathrm{Zr}$-based composite with in situ formed ductile dendritic crystalline phase that undergoes uniaxial compressions under quasi-static and dynamic strain rates. The underlying mechanism is proposed based on the concept of shear-band toughness that measures the critical energy dissipated in shear band.

\section{Experimental}

The normal composition of $\mathrm{Zr}_{39.6} \mathrm{Ti}_{33.9} \mathrm{Nb}_{7.6} \mathrm{Cu}_{6.4} \mathrm{Be}_{12.5}$ was chosen for our study. Ingots of this composition were prepared by arc melting the mixture of $\mathrm{Zr}, \mathrm{Ti}, \mathrm{Nb}, \mathrm{Cu}$ and Be with purity higher than $99.9 \mathrm{wt} \%$ under a Ti-gettered argon atmosphere. The rod like samples with $5 \mathrm{~mm}$ in diameter and about $7 \mathrm{~cm}$ in length were obtained by suctioning the melt into the copper mould in an argon atmosphere. The phases of the samples were checked by X-ray diffraction (XRD) in a Philips PW 1050 diffractometer using CuKa radiation. As shown in Fig. 1(a), the sharp diffraction peaks for the crystalline phase are superimposed on the broad diffuse scattering amorphous maxima. The crystalline phase is checked to be the $\beta-\mathrm{Zr}$ phase that has a body centered cubic (bcc) structure. The morphology of the chemically etched specimen observed under the optical microscope is showed in Fig. 1(b). The crystalline phases, characterized by the dendritic morphology, are homogeneously distributed within the continuous glass matrix. By analyzing 

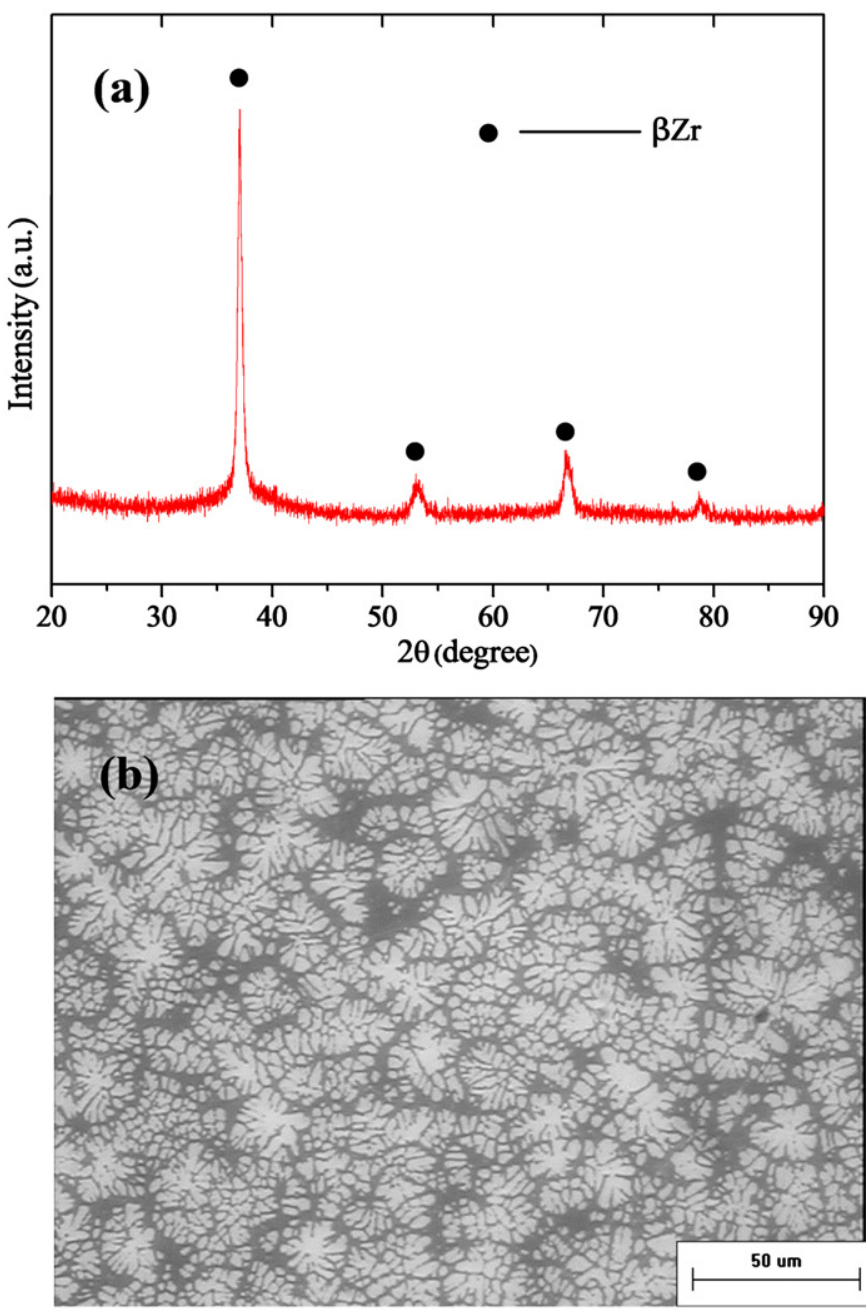

Fig. 1. (a) $\mathrm{XRD}$ pattern of the $\mathrm{Zr}_{39.6} \mathrm{Ti}_{33.9} \mathrm{Nb}_{7.6} \mathrm{Cu}_{6.4} \mathrm{Be}_{12.5}$ composite and (b) microstructure of the $\mathrm{Zr}_{39.6} \mathrm{Ti}_{33.9} \mathrm{Nb}_{7.6} \mathrm{Cu}_{6.4} \mathrm{Be}_{12.5}$ composite observed under optical microscope.

the contrast of the image, the volume fraction of the crystalline phase in this BMG matrix composite is about $70 \%$. This means that the crystalline phase takes most part of the specimen.

The compressive tested specimens were cut from the as cast cylindrical rods using electrical discharge machining. The specimen end surfaces were polished to be flat and parallel to each other, and perpendicular to the loading axis. Quasistatic compressive experiments were conducted with an MTS-810 machine at a strain rate of $8.3 \times 10^{-4} / \mathrm{s}$. The tested specimens have length of $10 \mathrm{~mm}$ (aspect ratio 2). Dynamic uniaxial compressive experiments at a strain rate of $1.9 \times 10^{3} / \mathrm{s}$ were performed using the split Hopkinson pressure bar (SHPB). In order to get the homogeneous distribution of the stress before fracture, the smaller aspect ratio of 1 is used for this case. To obtain reliable macroscopic stress-strain curves of the composite at both strain rates, at least three specimens were performed for each case. After testing, the fracture surfaces and the lateral surfaces of all the fractured samples were checked by the FEI Sirion high-resolution scanning electron microscope (SEM).

\section{Results}

\subsection{Stress-strain curves}

Typical stress-strain curves in quasistatic and dynamic compressions of the composite are shown in Fig. 2. Under the quasistatic compression, the composite exhibits obvious strain hardening after yielding at a stress level of about $1.5 \mathrm{GPa}$, as shown from curve (a). This strain hardening phenomenon is hardly observed for monolithic BMGs. The maximum strength approaches $2.3 \mathrm{GPa}$, and the plasticity of about $30 \%$ is available. Compared with $2 \%$ plastic strain for the typical BMG vit $[40,41]$, the plasticity has been improved a lot. Curve (b) shows the dynamic result. After the elastic response, the specimen fractures immediately and shows nearly no plasticity. The material exhibits a "quasi-brittle" behavior. It can be seen obviously that with the increasing strain rate, the fracture strain of the composite decreases from 0.30 to 0.05 . These results are consistent with the previous studies of the similar composites [29-31].

\subsection{Lateral and fracture surface morphologies}

Fig. 3(a) shows the macroscopic deformation of the quasistatic compressive specimen. The deformed specimen becomes shorter and thicker than the undeformed one. This confirms that the specimen experiences remarkable plastic deformation before fracture. Fig. 3(b) displays the SEM image of the lateral surface of the quasistatic specimen. The area marked by the rectangle in Fig. 3(b) is magnified and shown in Fig. 3(c). Profuse shear bands (indicated by the arrows) with different orientation are obvious on the lateral surface, in agreement with the considerable plasticity. Images for dynamic specimen are shown in Fig. 3(d)-(f). Macroscopically, the fractured specimen has nearly the same size as the undeformed one, as shown in Fig. 3(d). This means that the sample exhibits nearly no plasticity before fracture. Fig. 3(f) shows the details corresponding to the area marked in Fig. 3(e). In contrast to the quasistatic specimen, the multiplication of the shear bands is absent on the lateral surface of the dynamic specimen.

Fig. 4(a) and (b) show the typical fracture surfaces of the quasistatic and dynamic specimens, respectively. No vein patterns can be observed on the fracture surface under both strain rates. This may attribute to the crystalline dendritic phases which take most part of the composite. Compared with dynamic case, two different characteristic features of the quasistatic fracture surface morphology can be observed: (1) the fracture surface is relatively rough, (2) more traces of shear flow can be observed. These indicate that the shear induced fracture patterns also depends on the loading rate. This observation is consistent with the findings of Qiao et al. [31].

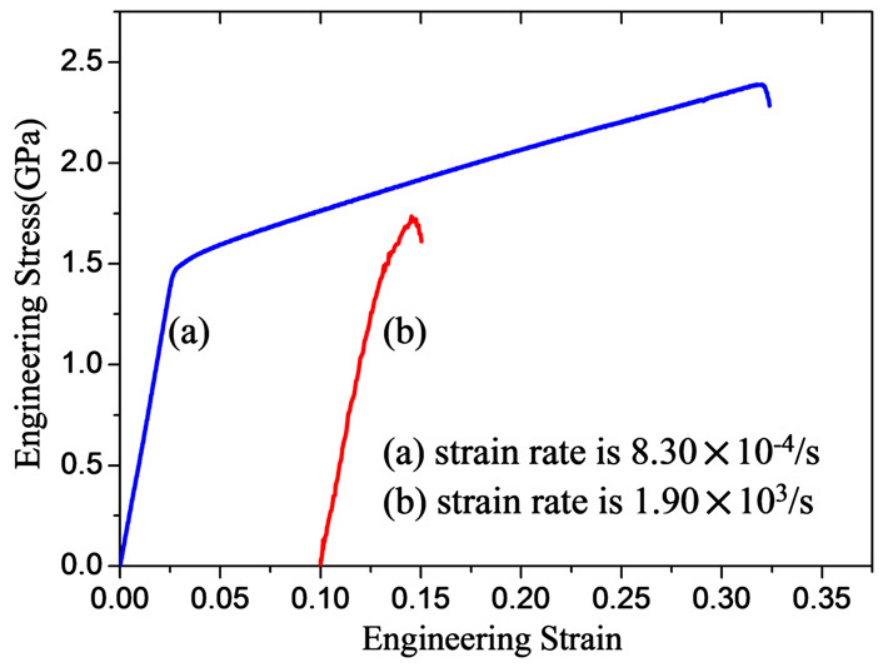

Fig. 2. Typical stress-strain curves of the composite under different strain rates. Line (a) loading with a strain rate of $8.3 \times 10^{-4} / \mathrm{s}$ and line (b) with the strain rate of $1.90 \times 10^{3} / \mathrm{s}$. 

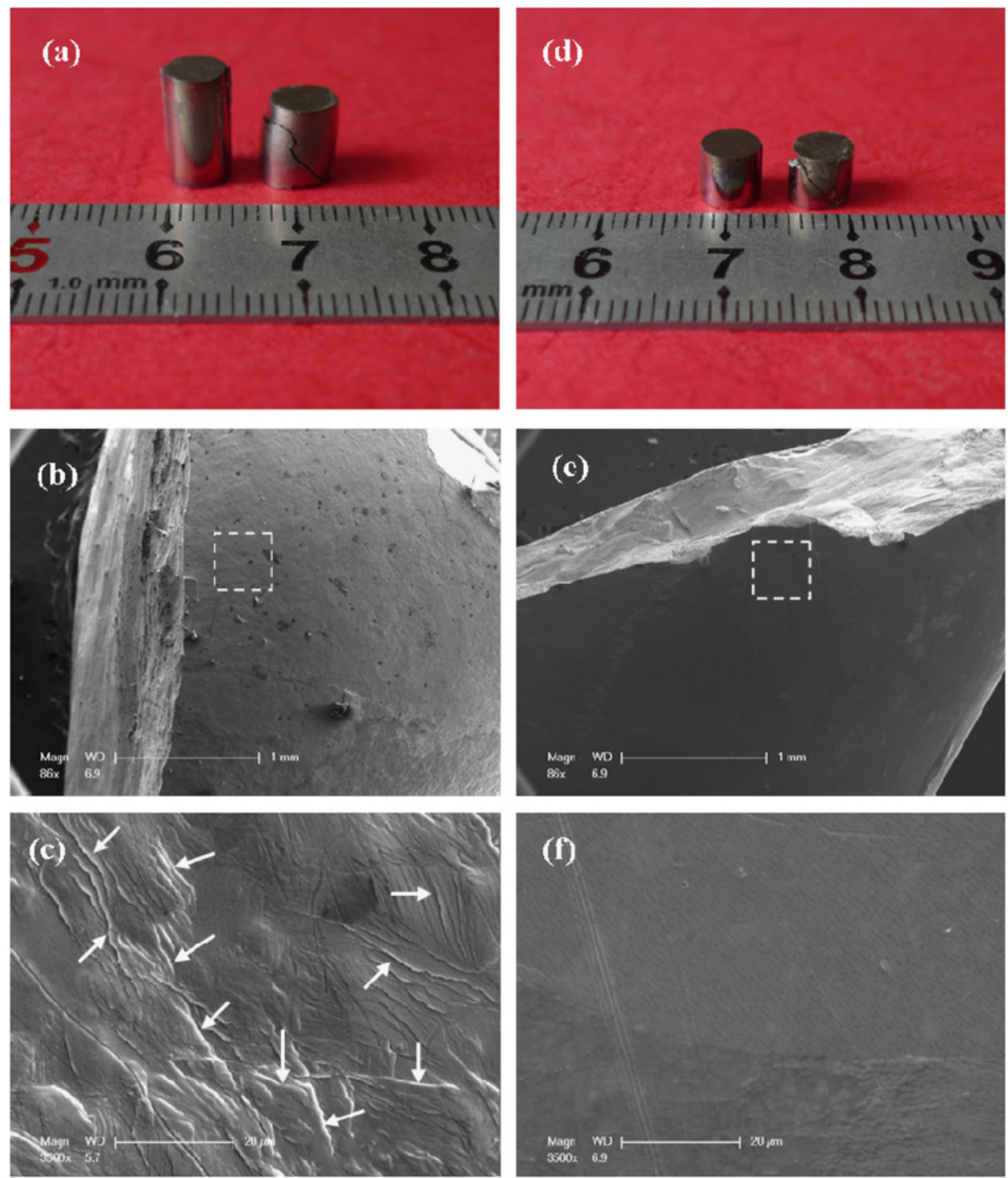

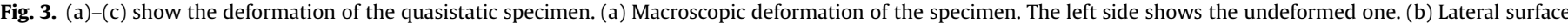

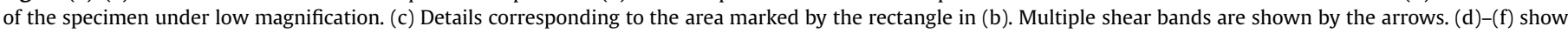

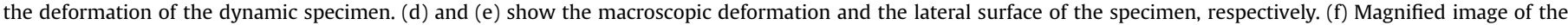
area marked by the rectangle in (e).
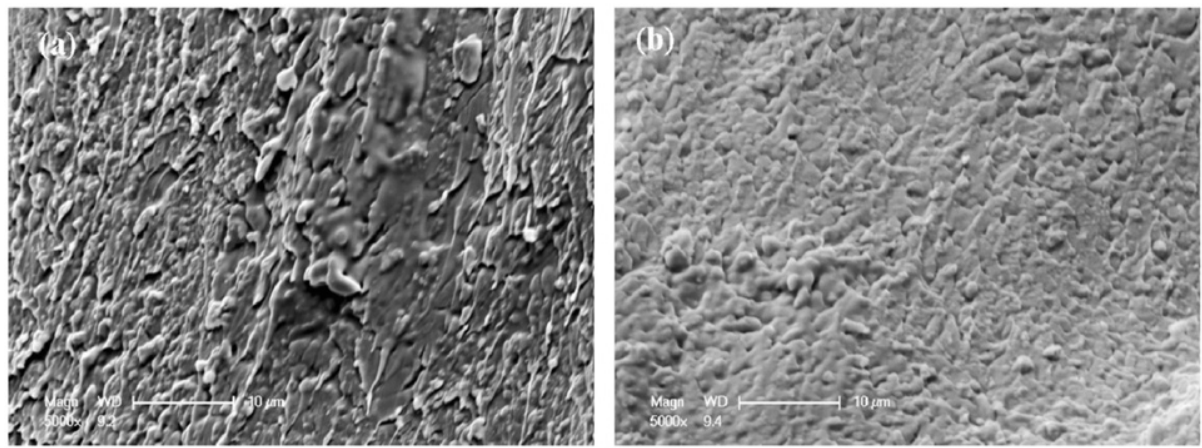

Fig. 4. Fracture surfaces of (a) the quasistatic compressive specimen and (b) the dynamic compressive specimen.

\section{Discussion}

From the above experimental results and observations, it can be seen that the density of shear bands and fracture morphology are strongly affected by the strain rate. However, the mechanisms for this rate dependent shear banding behavior are not well understood.
Firstly, we discuss the formation of shear bands in the composite. Many available investigations have demonstrated that the local coalescence of the free volume is an important reason for the formation of shear bands at the early deformation stage of BMGs [13-15,33-39]. In the deformation model developed by Spaepen [33], the free volume is created by an applied shear stress and annihilated by a series of atomic jumps. Based on the Spaepen's 
model, Liu et al. [42] have pointed out that the concentration of the free volume will increase a lot to a constant value once the BMG yields. When the BMG matrix composite is subjected to the external load, the interfaces between the crystalline phase and the glassy matrix are the areas of stress concentration. This stress concentration is created either by difference in elastic properties of the crystalline phase and the matrix, or by difference in yield strength of the two phases. The higher stress in these areas makes the local BMG matrix yields earlier than other parts. A higher concentration of free volume will be generated in the BMG matrix near the interface. As a result, shear bands are generated much easier in these areas. In other words, the ductile phase will serve as heterogeneous sites for the initiation of individual shear band. In the present study, we suppose that the shear bands are initiated from the interfaces between the crystalline phases and the matrix under both strain rates.

Once are initiated, shear bands will propagate in the composite. The BMG matrix composites contain the amorphous phases and the crystalline phases. When shear bands propagate in these two phases, it will dissipate energy in the shear bands. Previous studies have demonstrated that these two phases have different energy dissipation mechanisms of the shear band [43-45]. In addition to conventional thermal/energy and momentum/viscous dissipation in the crystalline alloy, the free volume dissipation should be involved in the BMG matrix due to the unique atomic structure. Once the energy released overcomes the critical plastic energy $\Gamma_{c}$ dissipated in a shear band, the shear banding will mature as a runway shear crack. $\Gamma_{c}$ therefore determines the shear band susceptibility, which measures the intrinsic resistance of materials to propagation of shear bands. The concept of shear band toughness was introduced in crystalline alloys [43,44] and metallic glasses [45] as $K_{c}=\sqrt{2 G \Gamma_{c}}$. Here, $G$ is the shear modulus. A larger $K_{c}$ indicates more significant resistance of materials to the propagation of the shear bands. In this regard, the shear banding behavior of the composite maybe determined by the mismatch between the shear band toughness of these two phases. If the shear band toughness of the crystalline phase is higher than the glassy phase, the crystalline phase will acts as an obstacle for the propagation of the shear band. The shear band may be hindered or deflected by the crystalline phase when the shear band encounters them. This leads to the generation of multiple shear bands. If the shear band toughness of the crystalline phase is close to the glassy phase, the shear band will propagate with no obstruction. The shear band will cut through the crystalline phase directly. As a result, single shear fracture happens. Finally, the rate effect of the shear banding behavior can be characterized by the rate effect of the shear band toughness of the crystalline phase and the glassy phase.

Based on the thermo-plastic analysis of the shear bands, the shear band toughness of the crystalline alloys is given by Grady $[43,44]$

$K_{c}=\sqrt{2 G \frac{\rho c}{\alpha}\left(\frac{9 \rho^{3} c^{2} \chi^{3}}{\tau_{y}^{3} \alpha^{2} \dot{\gamma}}\right)^{1 / 4}}$

where $\rho$ is the density of the material, $\alpha$ is the thermal softening coefficient, $c$ and $\chi$ are bulk specific heat and thermal diffusivity coefficients, respectively, $\dot{\gamma}$ is the shear strain rate and $\tau_{y}$ is yield strength. For the parameters of typical crystalline alloys, we can calculate the shear band toughness $K_{c}$ as a function of $\dot{\gamma}$ based on Eq. (1). Here, we only estimate the order of magnitude of the shear band toughness of the dendrite in the BMG composite. Szuecs et al. [46] measured the values of the shear modulus, yield strength and density of the dendrite in the BMG composite which has the similar composition as the present study. The shear modulus is $22.7 \mathrm{GPa}$, the compressive yield strength is $550 \mathrm{MPa}$ and $6500 \mathrm{~kg} / \mathrm{m}^{3}$ for the density. Here, we take the order of the $\mathrm{G}$ for $10^{10} \mathrm{~Pa}, \tau_{y}$ for $10^{8} \mathrm{~Pa}, \rho$ for $10^{3} \mathrm{~kg} / \mathrm{m}^{3}$. Otherwise, the parameters of 11 kinds of general crystalline alloys were given in Grady's work [44]. Based on these parameters, we estimate the order of the other parameters of the dendrite as follows: $c \sim 10^{2} \mathrm{~J} /$ $\mathrm{kg} \mathrm{K}, \alpha \sim 10^{-4} / \mathrm{K}, \quad \chi \sim 10^{-4} \mathrm{~m}^{2} / \mathrm{s}$. Inserting the parameters of the dendrite into Eq. (1), we get the shear band toughness $K_{c}$ of as a function of $\dot{\gamma}$ for the dendrite phase. The order of the shear band toughness is $10^{1} \mathrm{MPa} \mathrm{m}^{1 / 2}$ for the strain rate of $1.0 \times 10^{3} \mathrm{~s}^{-1}$. The corresponding critical dissipate energy $\Gamma_{c}$ is $10^{1} \mathrm{KJ} / \mathrm{m}^{2}$, which is on the same order of Charpy impact toughness of the dendrite measured by Zachrisson et al. [47]. Under the strain rate of $8.3 \times 10^{-4} \mathrm{~s}^{-1}, K_{c}$ increases to $10^{2} \mathrm{MPa} \mathrm{m}^{1 / 2}$.

Considering the shear band stress softening due to both free volume creation and temperature rise, the implicit expression of the critical dissipation energy $\Gamma_{c}$ is given by Jiang and Dai. If only free volume softening is considered, the explicit expression of the shear band toughness can be obtained as follows [45]:

$K_{c}=\sqrt{2 G \frac{\tau_{y}}{\beta R}\left(\frac{9 \rho D^{3}}{\dot{\gamma} \tau_{y} \beta^{2} R^{2}}\right)^{1 / 4}}$

where $D$ is the diffusion coefficient of free volume concentration, $R$ describes the local dilatation ability, $\beta$ is free volume softening coefficient. Actually, Jiang and Dai have pointed out that the thermal effect plays a secondary role in the critical dissipation energy of the shear band in BMGs. Using the parameters in [45], we can estimate the order of shear band toughness of $K_{c} \sim 10^{0}-10^{1} \mathrm{MPa} \mathrm{m}^{1 / 2}$ for BMG matrix that also depends on the strain rates.

Fig. 4 shows the fracture morphologies at the quasistatic and dynamic strain rates. Since fracture morphology is created by shear band propagation, a close-up examination on the characteristic features of fracture morphology can help us understand the shear band propagation behaviors and fracture mechanisms. Many previous studies demonstrated that temperature rise within the shear band can be as high as a few thousand Kelvin [48-50]. This significant temperature rise causes considerable softening of material within the shear band. As a result, the material within the shear band flows like a fluid. More traces of shear flow in the quasistatic fracture surface indicates that a higher temperature rise is obtained within the shear band. If we take the shear fracture plane as a source of zero thickness in an infinite medium, the temperature rise $(\Delta T)$ profile along the width direction of shear bands, $x$, and with the time $t$, can be estimated by the thin-film solution of the heat diffusion equation [50]:

$\Delta T=\left(\frac{H}{2 \rho c \sqrt{\pi \chi}}\right) \frac{1}{\sqrt{t}} \exp \left(\frac{-\chi^{2}}{4 \chi t}\right)$

where $H$ is the heat content (energy per unit area) of the band generated by shear. It can be given by $H=\beta \tau_{y} \psi_{c}$, where $\beta(\cong 0.9)$ is the work-heat transformation coefficient, $\psi_{c}$ is the critical shear displacement in the shear band. As mentioned above, the shear banding process is a dissipation system. The critical energy $\Gamma_{c}$ dissipated within the shear band as deformation proceeds to a critical displacement $\psi_{c}$ can be identified as $\Gamma_{c}=(1 / 2) \tau_{y} \psi_{c}$. Then, the heat content $H$ can be related to the $\Gamma_{c}$ and shear band toughness $K_{c}$ by

$H=2 \beta \Gamma_{c}=\frac{\beta K_{c}^{2}}{G}$

According to the estimation of the order of magnitude of shear band toughness, the heat content is on the order of magnitude of $10^{4} \mathrm{~J} / \mathrm{m}^{2}$ at the quasi-static strain rate, while $10^{2} \mathrm{~J} / \mathrm{m}^{2}$ at the dynamic case. Here, we consider three typical values of the time $t$ as $100 \mathrm{~ns}, 1 \mu \mathrm{s}$ and $100 \mu \mathrm{s}$ for the present BMG composite. Fig. 5 presents the distribution of temperature rises away from the shear 

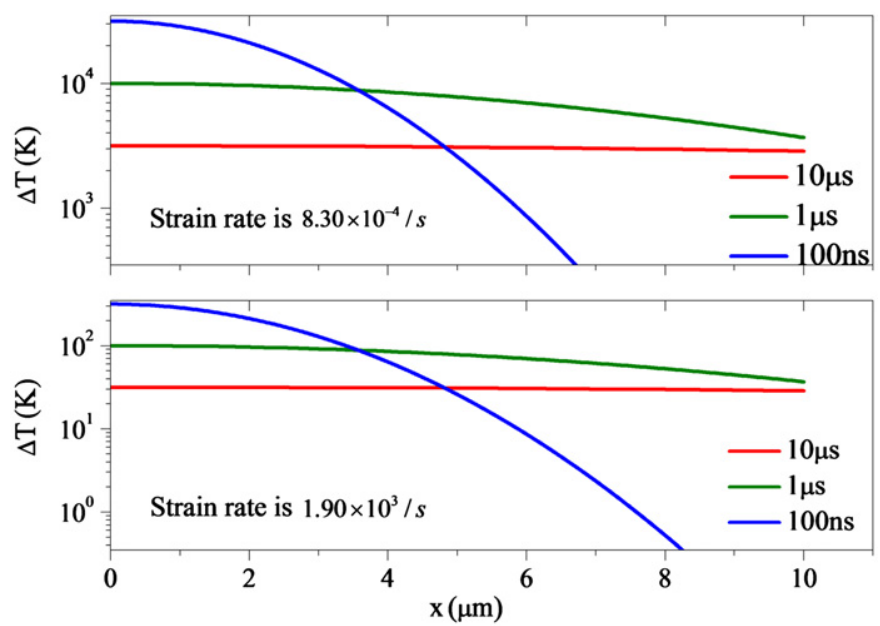

Fig. 5. The temperature rise varies with the distance from the shear band at the time $t=100 \mathrm{~ns}, 1 \mu \mathrm{s}$ and $10 \mu \mathrm{s}$. The upper part of shows the quasistatic case, while the lower part corresponds to the dynamic case.

band center at three different characteristic times. The upper part of this figure shows the quasistatic case, while the lower part corresponds to the dynamic case. It can be seen clearly from this figure that the temperature rise under the quasistatic compression is higher than that in the dynamic situation.

Based on the analysis above, the possible physical reason of the rate dependent shear banding behavior and the resultant ductileto-brittle transition in the BMG matrix composite can be unveiled. The mismatch between the shear band toughness of these two phases decreases with increasing strain rate. The shear band toughness of the crystalline dendrite is much higher than that of the amorphous matrix in the quasistatic condition, while these values become close for the dynamic situation. Due to their much higher shear band toughness under quasistatic loading, the dendrites have strong resistance to the propagation of shear bands. Therefore, the shear bands propagated in the matrix may be hindered or deflected when they encounter the dendrites. This is evidenced by the experimental observations of Hufnagel et al. [51], Sun et al. [52] and Hofmann et al. [24]. Simultaneously, new shear bands continue to nucleate in the interfaces. These two aspects contribute to the generation of the multiple shear bands, as found in Fig. 3(c). These profuse shear bands accommodate much plastic strain, leading to a considerable macroscopic plasticity. However, the dendrites have the shear band toughness close to the matrix under dynamic compression. This indicates that the resistance to the shear band propagation of the dendrites decreases dramatically under the dynamic strain rate. Once the shear bands encounter the dendrites, they will cut through the dendrites relatively easily. There is no opportunity for the new shear bands to be generated in the interfaces. Multiple shear bands are absent and single shear fracture happens, as shown in Fig. 3(e) and (f). Macroscopically, the composite exhibits negligible plasticity. What is further, with increasing strain rate, the shear band toughness $K_{c}$ decreases. Under quasistatic strain rate, a larger $K_{c}$ denoting higher energy dissipation in the shear band leads to a significant temperature rise and considerable plastic flow. This is the reason for the experimental observation that more traces of flow appear on the quasistatic facture surface, seen from Fig. 4.

\section{Conclusions}

The compressive behavior of $\mathrm{Zr}_{39.6} \mathrm{Ti}_{33.9} \mathrm{Nb}_{7.6} \mathrm{Cu}_{6.4} \mathrm{Be}_{12.5}$ bulk metallic glass matrix composite with in situ formed ductile dendritic crystalline phase was investigated at quasistatic and dynamic strain rates. The results demonstrate that the propagation behavior of shear bands and the fracture of this material are strongly affected by the strain rate. The multiplication of shear bands can be observed under quasistatic strain rate, while single shear banding occurs in the dynamic case. The order of shear band toughness of these two phases varies with the strain rate is estimated. The mismatch between the shear band toughness of the crystalline phase and amorphous phase is found to determine the shear banding behavior. More traces of shear flow in the quasistatic fracture surface imply a higher temperature rise occurred in the shear-induced fracture process, which is due to the higher shear band toughness.

\section{Acknowledgments}

Financial support is from the NSFC (Grants nos. 11132011, $11002144,11021262,11023001,11202221)$, the National Natural Science Foundation of China-NSAF. Grant no:10976100 and the National Key Basic Research Program of China (Grant no. 2012СВ937500)

\section{References}

[1] A.L. Greer, Science 267 (1995) 1947-1953.

[2] J.F. Löffler, Intermetallic 11 (2003) 529-540.

[3] J. Zhang, J.M. Park, D.H. Kim, H.S. Kim, Mater. Sci. Eng. A 449-451 (2007) 290-294.

[4] V. Keryvin, K.E. Prasad, Y. Gueguen, J.-C. Sanglebœuf, U. Ramamurty, Phil. Mag. 88 (2008) 1773-1790.

[5] M.M. Trexler, N.N. Thadhani, Prog. Mater. Sci. 55 (2010) 759-839.

[6] W.H. Wang, Prog. Mater. Sci. 57 (2012) 487-656.

[7] R.D. Conner, R.B. Dandliker, V. Scruggs, W.L. Johnson, Int. J. Impact. Eng. 24 (2000) 435-444.

[8] H.S. Kim, H. Kato, A. Inoue, H.-S. Chen, S.I. Hong, Mater. Trans. 45 (2004) 1228-1232.

[9] A. Inoue, A. Takeuchi, Acta Mater. 59 (2011) 2243-2267.

[10] E. Axinte, Mater. Des. 35 (2012) 518-556.

[11] X. Huang, Z. Ling, Z.D. Liu, H.S. Zhang, L.H. Dai, Int. J. Impact. Eng. 42 (2012) $1-10$.

[12] C.T. Liu, L. Heatherly, D.S. Easton, C.A. Carmichael, J.H. Schneibel, C.H. Chen, J.L. Wright, M.H. Yoo, J.A. Horton, A. Inoue, Metall. Mater. Trans. A 29 (1998) 1811-1820.

[13] L.H. Dai, M. Yan, L.F. Liu, Y.L. Bai, Appl. Phys. Lett. 87 (2005) 141916.

[14] A.J. Cao, Y.Q. Cheng, E. Ma, Acta Mater. 57 (2009) 5146-5155.

[15] M.Q. Jiang, L.H. Dai, J. Mech. Phys. Solids 57 (2009) 1267-1292.

[16] W.J. Wright, M.W. Samale, T.C. Hufnagel, M.M. Leblanc, J.N. Florando, Acta Mater. 57 (2009) 4639-4648.

[17] S.X. Song, X.L. Wang, T.G. Nieh, Scripta Mater. 62 (2010) 847-850.

[18] A. Klaumünzer, R. Maa, J.F. Löffler, J. Mater. Res. 26 (2011) 1453-1463.

[19] C.C. Hays, C.P. Kim, W.L. Johnson, Phys. Rev. Lett. 84 (2000) 2901-2904.

[20] H.C. Yim, R.D. Conner, F. Szuecs, W.L. Johnson, Acta Mater. 50 (2002) 2737-2745.

[21] J.G. Lee, H.S. Kim, S. Lee, N.J. Kim, Mater. Sci. Eng. A 449-451 (2007) 176-180

[22] M.E. Siegrist, J.F. Löffler, Scripta Mater. 56 (2007) 1079-1082.

[23] J. Eckert, J. Das, S. Pauly, C. Duhamel, J. Mater. Res. 22 (2007) 285-301.

[24] D.C. Hofmann, J.-Y. Suh, A. Wiest, G. Duan, M.-L. Lind, M.D. Demetriou, W.L. Johnson, Nature 451 (2008) 1085-1090.

[25] Y. Wu, Y.H. Xiao, G.L. Chen, C.T. Liu, Z.P. Lu, Adv. Mater. 22 (2010) 2770-2773

[26] J.L. Cheng, G. Chen, F. Xu, Y.L. Du, Y.S. Li, C.T. Liu, Intermetallic 18 (2010) 2425-2430.

[27] M. Shanthi, M. Gupta, A.E.W. Jarfors, M.J. Tan, Mater. Sci. Eng. A 528 (2011) 6045-6050.

[28] C.Y. Son, G.S. Kim, S.B. Lee, S.K. Lee, H.S. Kim, H. Huh, S.H. Lee, Metall. Mater. Trans.A 43 (2012) 4088-4096.

[29] D.G. Lee, Y.G. Kim, B. Hwang, S. Lee, Y.T. Lee, Mater. Sci. Eng. A 472 (2008) 316-323.

[30] J.W. Qiao, Y. Zhang, P. Feng, Q.M. Zhang, G.L. Chen, Mater. Sci. Eng. A 515 (2009) 141-145.

[31] J.W. Qiao, P. Feng, Y. Zhang, Q.M. Zhang, P.K. Liaw, G.L. Chen, J. Mater. Res. 25 (2010) 2264-2270

[32] Y.L. Bai, J. Mech. Phy. Solids 30 (1982) 195-207.

[33] F. Spaepen, Acta Metall. 25 (1977) 407-415.

[34] A.S. Argon, Acta Metall. 27 (1979) 47-58.

[35] M.L. Falk, J.S. Langer, Phys. Rev. E 57 (1998) 7192-7205

[36] L. Anand, C. Su, J. Mech. Phys. Solid 53 (2005) 1362-1396.

[37] Y.F. Gao, Modelling Simul. Mater. Sci. Eng. 14 (2006) 1329-1345. 
[38] Y.F. Gao, B. Yang, T.G. Nieh, Acta Mater. 55 (2007) 2319-2327.

[39] B. Dodd, Y.L. Bai (Eds.), second ed.,Elsevier, London, 2012.

[40] H.A. Bruck, T. Chrisman, A.J. Roskis, W.L. Johnson, Scripta Mater. 30 (1994) 429-434.

[41] L.F. Liu, L.H. Dai, Y.L. Bai, B.C. Wei, J. Eckert, Mater. Chem. Phys. 93 (2005) 174-177.

[42] L.F. Liu, L.H. Dai, Y.L. Bai, B.C. Wei, J. Non-Cryst. Solids 351 (2005) 3259-3270.

[43] D.E. Grady, J. Mech. Phys. Solid 40 (1992) 1197-1215.

[44] D.E. Grady, Mech. Mater. 17 (1994) 289-293.

[45] M.Q. Jiang, L.H. Dai, Acta Mater. 59 (2011) 4525-4537.
[46] F. Szuecs, C.P. Kim, W.L. Johnson, Acta Mater. 49 (2001) 1507-1513.

[47] C. Zachrisson, H. Kozachkov, S. Roberts, G. Kaltenboeck, R.D. Conner, M. Demetriou, W.L. Johnson, J. Mater. Res. 26 (2011) 1260-1268.

[48] J.J. Lewandowski, A.L. Greer, Nat. Mater. 5 (2006) 15-18.

[49] B. Yang, M.L. Morrison, P.K. Liaw, R.A. Buchanan, G.Y. Wang, C.T. Liu, M. Denta, Appl. Phys. Lett. 86 (2005) 141904.

[50] H.W. Zhang, G. Subhash, S. Maiti, J. Appl. Phys. 102 (2007) 043519.

[51] T.C. Hufnagel, C. Fan, R.T. Ott, J. Li, S. Brennan, Intermetallics 10 (2002) $1163-1166$.

[52] G.Y. Sun, G. Chen, G.L. Chen, Mat. Sci. Forum 539-543 (2007) 1943-1950. 